\title{
Predictors of Investors' Participation in the Egyptian Stock Market: Application of Theory of Planned Behavior
}

\author{
Dalia EI Mosalamy ${ }^{1, *}$, Madiha Metawie ${ }^{1,2}$ \\ ${ }^{1}$ Faculty of Business Administration, Economics and Political Science, British University in Egypt \\ ${ }^{2}$ Business Department, Faculty of Commerce, Ain Shams University, Cairo, Egypt \\ *Corresponding author: Dalia.Elmosalamy@bue.edu.eg
}

\begin{abstract}
Despite the opportunities of growth for the Egyptian stock market, it still offers limited potential to attract investors. This paper explores how various factors related to attitudes, subjective norms and perceived behaviour control as indicted by the theory of planned behaviour affect stock market participation (SMP) in the emerging market of Egypt. The aim of this paper is to study how the influence of factors as financial literacy, risk, influence of others, confidence in the regulator among others, affect consumers' investment decision to participate in the stock market. A pilot study when combined with literature review revealed eight factors that might affect the investors' intention and behaviour in the Egyptian stock market. The study then apply TPB to develop a comprehensive model to include the most important factors that may have a strong potential to enhance the equity holding behaviour and explain SMP in the emerging market of Egypt; a market with a lot of potential but rarely studied. This model can be further tested across different developing markets as well. The study concluded that investment intention could predict the actual investment in the stock market (which represents behaviour). Nevertheless, the behaviour is not determined by only those factors tested. Other moderating factors (as change in interest rates, taxes, transaction costs...) can be examined to test the effect on SMP, which opens the room for future research.
\end{abstract}

Keywords: investor's behaviour, hassle factor, investor intention, investor financial literacy, financial well-being, perceived investments of significant others, risk avoidance, regulatory perception, stock market participation, theory of planned behaviour

Cite This Article: Dalia El Mosalamy, and Madiha Metawie, "Predictors of Investors' Participation in the Egyptian Stock Market: Application of Theory of Planned Behavior." Journal of Business and Management Sciences, vol. 6, no. 3 (2018): 118-125. doi: 10.12691/jbms-6-3-9.

\section{Introduction}

Over the last decade, stock markets have received a great deal of attention being a main source of financial development and economic growth. Despite the documented benefits of capital markets to economic growth, Stock market participation levels across countries are still not up to normative standards [1]. With respect to Egypt for example, and despite the very high savings rates and the positive look for the future of investments, and with continuous amendments in Capital market laws and regulations, we argue that there is still a low penetration of Egyptian Stock Market especially when compared to savings in real estate and gold.

Examining the behaviour of financial markets and their players is of great interest and importance to most scholars. Examining the factors that may affect the stock market participation (SMP hereafter) in developed markets are controversial too. Many factors including income, financial literacy, education, risk tolerance amongst others have shown high correlation with SMP in developed markets $[2,3,4]$. However, limited studies pertaining to emerging markets where these factors along with their effects on stock market participation have been Cited. For example, Ulku and Ikizlerli [5] argue that EEMENA (Eastern Europe, Middle East, North Africa) region has been surprisingly neglected in literature; despite it hosts those emerging economies that are most dependent on foreign capital inflows.

In this paper, we are testing the influence of selected factors on the individuals' investment decisions, specifically in the stock market based on the Theory of Planned Behavior, then attempting to develop a model to represent relationships between those selected factors.

Importance of the study; the purpose of this study is to shed more light to the factors that can enhance the limited stock market participation in general and Egypt in specific. The study aims to identify the critical factors that may shape investors behaviours towards SMP. Additionally, the study itself is focusing on the emerging market of Egypt; a market that has a lot of potential for growth and profitable opportunities, yet the amount of 
research is very limited. This study is of value to researchers and practitioners and it can definitely serve as a base for more studies in the emerging markets in general and the Middle East in specific.

This paper proceeds as follows. Section 2 briefly sheds some lights on the Egyptian stock market, history and main shocks and challenges. Section 3 presents a literature review on the drivers of SMP. Section 4 presents the data and methodology used. Section 5 presents the results and discussion followed by conclusions, implications, limitations and areas for further research in Section 6.

\section{The Stock Market in Egypt}

The Egyptian Stock market is one of the oldest capital markets in the world, and it comprises two exchanges that have been recently integrated allowing investors to have access to stocks listed on both of them; Alexandria Stock Exchange, founded in 1888, and Cairo Stock Exchange established in 1903. According to the official Egyptian stock exchange website (www.egyptse.com), it was the fifth most active stock exchange worldwide in 1940s, prior to the nationalization of industry and choosing the central planning policies in the early 1950 s, which led to a significant reduction in the market activities, resulting in a market that remained dormant throughout the 1980s. In the 1990s, and with the introduction of the Egyptian capital market law, the Egyptian market was revived and since then it has been considered the premier capital market in the Middle East and North Africa [6].

With the unexpected political uprisings in 2011, according to Omran, [7], those events had a negative impact on the Egyptian stock market as it led to its closure for almost three months after losing 16 percent of its market capitalization in two sessions on January 26 and 27 , 2011. Trade was suspended till March 23, 2011. The EGX30 index lost 74 percent of its value in Egyptian pounds in the period from July 30, 2009 to April 30, 2013. The index went down in value from 674 to 173.5 billion Egyptian pounds. Since then, efforts are being made, with continuous refinements in the Egyptian capital market, laws and regulations, fiscal and monetary policies amendments, but still investors' confidence and participation was seriously shaken and its impact is still lingering.

\section{Literature Review}

A stock market can be a very sophisticated market place; however, it can be essential to the creation and development of a strong and competitive economy [5]. On an individual level, effective stock investments should, in theory, enhance individual's financial well-being in the long term. In reality, many families do not participate in the stock market. For example, Wang and Liao [8] studied the Chinese market, one of the highly prospering markets, concluded that the average stock market participation of Chinese households is only $17.5 \%$. Surprisingly a similar study conducted by Xia et al. [9] revealed that the SMP rate in the US is only $15 \%$ and in Europe is only $23 \%$.

Helmy and Wagdi [10] view that the investment decision, by itself, is not a complicated one, if only we were able to consider all costs associated with the investment decision, and then we could estimate its expected returns.

Other studies attempted to explain the drivers affecting investors' intention to participate in the stock market. Many psychological and empirical studies in finance have found that people are not always rational, and systematic cognitive biases will lead to deviations from inferences drawn by classic theory of finance [11]

Development of behavioral finance and theories about investors' attitudes and the way investors deal with different market variables and attitudinal factors related to the individual himself, are all used in literature to explain the psychology behind the trading behavior and SMP of the different investors $[2,12,13]$.

In our attempt to explain the relation between stock market participation and the intention, many studies cited the Theory of Planned Behavior (TPB) as one of the commonly cited theories that attempt to predict behavior in general $[14,15,16,17]$. The TPB is a socio-psychological behavioral theory extended from the theory of reasoned action (TRA). The latter assumes that a customer's intention, influenced by his or her attitudes and subjective norms, is the strongest indicator of his or her purchasing behavior $[18,19,20]$. However, the TPB overcame the limitation of the TRA and included behaviors where individual have incomplete faculty of using one's will or situation where they have incomplete control of their behavior. Perceived behavioral control (PBC) was added to the two existing determinants of intention mentioned in the TRA. $[21,22]$. As a common rule, the more favorable the attitude and subjective norm, and the greater the perceived behavior control (PBC), the stronger should be the person's intention to perform the behavior in question and more likely the behavior itself.

The more recent definition of attitude is the degree of favorableness and un-favorableness of an individual feeling towards a psychological object [23]. Ajzen [24] indicated that attitudes consist of various beliefs that affect one's overall behavioral intentions. Gopi M., and Ramayah T. [16] added that attitude have long been identified as a construct that guides future behavior or the cause of intention that ultimately leads to a particular behavior. Attitudes are restricted to those that are salient and therefore easily brought to mind by consumers, Hegner et al., [14]. Many studies have shown the significant effect of attitude towards intention [14,15,16,17].

In the same regard, the Theory of Planned Behavior assumes that individual's behavior is highly affected by the perception of 'important others', which is represented by the subjective norms [25]. Hegner et al. [14] identified subjective norm as the individual's perceptions of general social pressure. If an individual recognises that significant others endorse (or disapprove of) the behavior, they are more likely to show the behavior (or not). Additionally, $\mathrm{PBC}$ refers to "the perceived ease or difficulty of performing the behavior" [24].

Several studies involving financial products have used investment intention as a dependent variable to measure the intention to invest [26,27]. TPB was also applied to measure consumer's intention towards mutual funds investments as Kaur and Kaushik [28] who used the theory of planned behavior, to examine the effect 
of awareness, attitude (perception for outcome) and socioeconomic conditions of an investor on his investment behavior towards mutual funds. The findings provided evidence that investment behavior could be explained with awareness, perception and socioeconomic characteristics of individual investors. Better awareness related to various aspects of mutual funds will have a positive effect on investment in mutual funds. Contrary to belief, risk perception for mutual funds had no effect on the investment decision. Further, socioeconomic characteristics such as age, gender, occupation, income and education of investors had an impact on the awareness about mutual funds.

Accordingly, and following the study of Ajzen [24], in the TPB, intentions precede behavior (represented in our study by actual equity holding) we can hypothesize that:

H1. Investment intention has a positive significant influence on equity holding.

There is considerable literature on the various variables, which may cause investors to intend and actually participate in the stock market.

With respect to the relation between the SMP and financial literacy, studies on this topic is relatively scarce. Lusardi and Mitchell [29] argue that financial illiteracy is common and people lack knowledge of basic economic principles. Similarly, Rooij et al. [30] added that the majority of households in US may possess basic financial knowledge but do not know the basics of risk diversification and concluded that financial literacy affects financial decision-making. These results agree with Campbell [31] who linked the low SMP to the little knowledge of stocks and the working of the stock market in general.

While studying individual knowledge, we need to differentiate between actual knowledge and individuals' assessments of their knowledge. Xia et al. [9] defines the objective knowledge as those possessed by the investor, while subjective knowledge is viewed as a belief about that state of knowledge.and presented evidence that there is a positive correlation between financial literacy and SMP. They also provided empirical evidence that both subjective and objective financial literacy positively influence SMP. The study of Sivaramakrishnan, et al. [32] considered consumer financial literacy a part of the perceived behaviour control and included in the TBP model. Accordingly, in this study we are hypothesizing;

$\mathrm{H} 2$. Objective financial literacy has a positive significant influence on investment intention.

H3. Subjective financial literacy has a positive significant influence on investment intention.

H4. Objective financial literacy has a positive significant influence on equity holding.

H5. Subjective financial literacy has a positive significant influence on equity holding.

Sivaramakrishnan et al. [32] view financial well-being as a state of being financially healthy and happy. This feeling could be derived from objective factors like wealth or income or on subjective factors as how people evaluate their lives. In this study, and following the work of Guiso and Sodini [1], only the objective criteria like wealth or income will be considered a proxy for financial well-being, and thus, we hypothesise the following;

H6. Financial well-being has a positive significant effect on the investment intention.
H7. Financial well-being has a positive significant effect on equity holding.

Many studies attempting to explain herding and asset price bubbles tend to focus on the perceived investments of significant others (PISO hereafter). Hong et al. [2] suggest that peers have a large impact on SMP and that investor sentiment which is not justified by economic fundamentals do influence security prices and SMP. Brown et al. [33] provided evidence consistent with the notion that individuals are more likely to participate in the stock market when their geographically proximate peers participate. Thus, the next hypothesis will be as follows:

H8. PISO have a positive and significant effect on investment intention.

"Investor confidence" has been a long-standing subject of interest among financial market observers, participants, researchers, and regulators. According to Guiso and Sodini [1], the decision to participate in financial markets requires not only, investors forming beliefs about the riskreturn trade-off, but also confidence in information sources, financial advisors, and the overall reliability of the financial system. Thus our hypothesis can be stated as:

H9. The perception of regulator has a positive significant influence on the investment intention.

Financial risk tolerance is commonly defined as the maximum amount of volatility one is willing to accept when making a financial decision. Sivaramakrishanan et al. [32] acknowledged risk avoidance as an important factor in savings and investments choices and argue that higher loss aversion is associated with a lower probability of SMP. A finding that agree with Lim et al. [27] who provided evidence that there is a negative relationship between stock market investment intention and risk avoidance in Singhapore.

Political risk, as a source volatility or systematic risk, is considered one of the determinants of market risk premium [34], a major determinant of domestic and foreign investment decisions and a variable that is able to explain disparities of stocks' returns between different countries [35].

Hekki and Kari [36] agree with Nebojsa et al. [36] in that that democracy and political risk do have impact on stock market returns in general, while the effect is more drastic in emerging markets specifically. They both documented evidence that stock market returns are negatively related to the level of political risk. Nebojsa et al. [37] view that Government instability is the source of political risk especially in emerging stock markets and that political risk and institutional indicators come first when multinational corporations confront decisions about where to invest.

Helmy and Wagdi [10] studied the effect of political changes on the Egyptian economy by studying the direct and indirect effect of political risk index on a number of important variables including the stock market participation, during the period from 2006 to 2015 . They concluded that the an increase in the level of political risk has negative effects on stock markets returns and volatilities; and that movements of international capital flows may aggravate the impact of this negative effect. Based on the literature presented, the below hypothesis is proposed;

H10. Risk avoidance have a significant negative influence on the investment intention. 
According to Bogan [38] information costs are very important when considering an investment decision. Actual or perceived costly information about the stock market also accounts for individuals not investing in the stock markets. From which our last hypothesis is:

H11. Hassle factor has a negative significant influence investment intention.

\section{Proposed Research Model}

Unlike many consumer products, savings and investments are seldom made on impulse. Extensive thought precedes investment decisions which strongly suggest that the TPB will be an ultimate as a theoretical framework. The theory is generally considered inappropriate for applications where consumption is involuntary, being required by social convention (opening a savings account) or forced by prior commitments (purchase of safety helmets), and where there is little thought involved (e.g. chocolates and other impulse purchase categories) [39].

Based on literature cited above, the researchers propose the following model (Figure 1) to investigate the applicability of TPB on investment intention and behavior (or equity holding) in Egypt. We have permitted the factors affecting SMP to be loosely grouped like in earlier studies $[40,41]$ conceptually while studying the effects on the focal constructs - investment intention and equity holding. This approach allows us to keep the effect of the individual factors while keeping the theoretical base of the study alive. The model illustrates the relationship between variables representing $\mathrm{ATB}, \mathrm{SN}$, and $\mathrm{PBC}$ which are the antecedents to the focal constructs of investment intention and behavior (or equity holding).

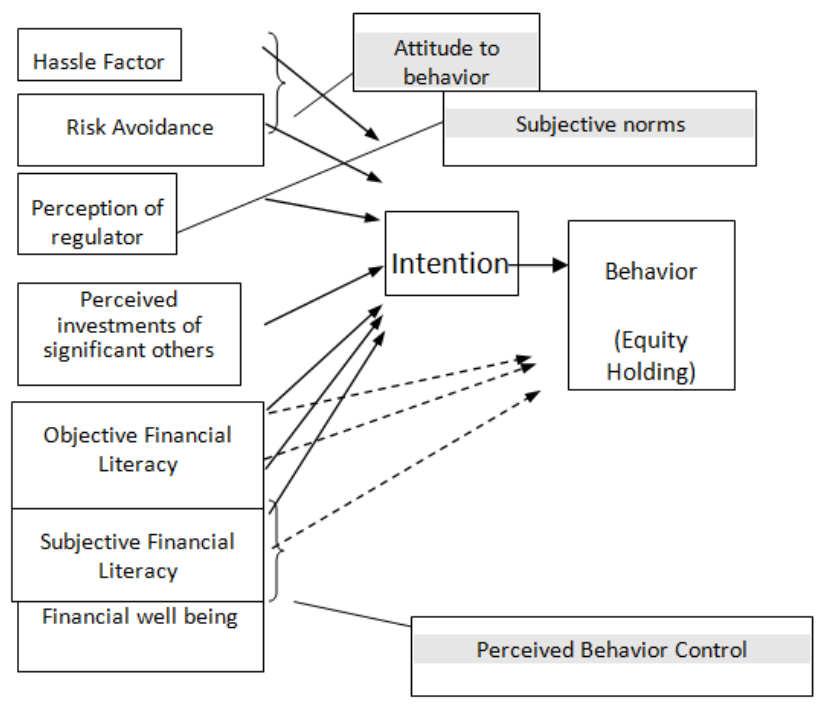

Figure 1. Conceptual model of stock market participation

\section{Data and Methodology}

Following the work of Johnson et al. [42], we have used a mixed methods research approach for the purpose of breadth and depth of understanding. Qualitative research followed by a quantitative survey-based study was used. The self-administered questionnaire was developed, pre-tested, and validated with the co-operation of several academicians familiar with research methods, as well as 20 experts, fund managers and bankers. Based on the literature review and the responses, eight variables were revealed, which were pooled into three distinct groups based on the TPB. This was done to enable the identification of the challenges and opportunities pertaining to emerging markets in general and the Egyptian market in specific. Testing the hypotheses proposed in the previous model required developing and administering the questionnaire to a convenience sample of consumers. Further assessing the reliability of the scales employed, and conducting a path analysis model was conducted to examine investment intentions adn behaviours among respondents.

\subsection{Sample}

A total of 650 questionnaires were distributed in CairoEgypt, out of which 478 agreed to participate in the study. After removing 74 incomplete questionnaires, we had a usable sample of 404 questionnaires yielding a reasonably high response rate of about 62.1 percent. Before distributing the questionnaire, all participants were assured that their participation was voluntary and anonymity was guaranteed. The age of participants ranged between 21 to over 50 years, the age from 21 to 30 comprised almost $46 \%$ of the sample. The sample had almost similar proportions of males (46 percent) versus females (54 percent), half of them (45\%) had finished their university degree. The percentage of university students was almost similar to the percentage of postgraduate (39\%) and (38\%) respectively. A percentage of $(42 \%)$ were employed and $(42 \%)$ were unemployed or housewives. These characteristics show a reasonable mix of demographic groups represented in the data.

\subsection{Measures}

Ten-part questionnaire was used to assess the study variables; perception of the regulator (6 items specifically written to match the Egyptian government perceptions regarding stock market). The internal consistency of this scale was (Cronbach's alpha $=0.85$ ). Risk avoidance included 3 items (one item was developed to include the political risk in Egypt and two items were adapted from Raju, [43]. The internal consistency of this scale was (Cronbach's alpha $=0.59$ ). In addition the hassle factor included three items (adopted [32]), the applied scale reported internal consistency of this scale was (Cronbach's alpha $=0.71)$. Perceived investment of significant others included five items (4 items adapted from Sivaramakrishnan and Rastogi, 2016 and 1 item adapted from Grønhøj et al., 2013). The internal consistency of this scale was (Cronbach's alpha $=0.71$ ) Financial wellbeing was measured using two items adopted from [44], and the applied scale reported internal consistency of this scale was (Cronbach's alpha $=0.57$ ). Moreover, Objective Financial Literacy was measured using seven items adopted from [30], the internal consistency of this scale was (Cronbach's alpha $=0.88$ ). Subjective Financial Literacy was measured using three items adopted from [45]. The internal consistency of this 
scale was (Cronbach's alpha $=0.48)$ Finally, Investment Intention was measured using five items adapted from $[46,47]$. The internal consistency of this scale was $($ Cronbach's alpha $=0.93)$. All items were measured on a five-point Likert scale. Answers ranged from 1 (strongly disagree) to 5 (strongly agree). Equity holding was measured using one item in the form of scale from 0 to 100 , this was used to indicate the behaviour towards Egyptian stock market participation, adopted from [32]). Finally, the demographic data collected were related to gender, age education and job level.

\subsection{Data Analysis and Results}

Recently, Structural Equation Modeling (SEM) has been commonly used among academics. SEM is typically suitable for theory testing. Hence, due to the nature and purpose of this research (i.e. conclusive descriptive research) SEM considered being appropriate to examine the research hypotheses. The researchers used AMOS (22.0). Although SEM includes regression analysis, however, it consists of number of other statistical techniques (e.g. path analysis and confirmatory factor analysis), as well as it allows for investigating the influence of any mediated variables

The correlation matrix indicated that there are significant positive relationships between behaviour and intention but not with financial wellbeing, objective and subjective financial literacy. This gives support for $\mathrm{H} 1$ but does not support H4, H5 and H7. In addition, there are significant positive relationships between POR, PISO, objective and subjective financial literacy; this gives support for $\mathrm{H} 2, \mathrm{H} 3, \mathrm{H} 8$ and $\mathrm{H} 9$. This means that these variables can create intention but not necessarily the behaviour towards stock market participation. In addition, it could be noted that behaviour of individuals is not only determined by these factors, therefore other variables could explain the individuals' behaviour towards stock market.

A stepwise regression analysis was conducted, first to determine the factors that predict intention, and the results are shown in Table 1.

It can be shown from Table 1 results that from the variables pertaining to $\mathrm{PBC}$, Subjective financial literacy was the only variable that predicts intention. POR, Risk avoidance were the only variables pertaining to attitude to predict the intention. Furthermore, PISO can predict significantly the intention towards stock market participation.

In addition, a Stepwise regression analysis was conducted to determine the factors that predict the behavior towards stock market participation, which is represented by equity holding. The results are shown in Table 2 below. The results indicated that the only factors that can predict the behavior are POR and Risk avoidance.
Table 1. Regression analysis on intention

\begin{tabular}{|lllll|}
\hline Independent Variables & $R^{2}$ & $\mathrm{~F}$ & $\mathrm{~B}$ & $\mathrm{t}$ \\
\hline Subjective Financial Literacy & 0.279 & 118.3 & 0.53 & 5.9 \\
& & & & 10.878 \\
\hline POR & .333 & 76.219 & .459 & 1.325 \\
& & & .243 & 9.412 \\
& & & & 4.988 \\
\hline Risk avoidance & .354 & 55.543 & .460 & 2.990 \\
& & & .262 & 9,563 \\
& & & -.144 & 5.413 \\
& & & & -3.101 \\
\hline PISO & .366 & 43.715 & .423 & 1.678 \\
& & & .248 & 8.451 \\
& & & -.133 & 5.124 \\
& & & .119 & -2.862 \\
& & & & 2.418 \\
\hline
\end{tabular}

dependent the depe** significant at 0.05 level.

Table 2. Regression analysis on behavior

\begin{tabular}{|lllll|}
\hline Independent Variables & $R^{2}$ & $\mathrm{~F}$ & $\mathrm{~B}$ & $\mathrm{t}$ \\
\hline POR & 0.049 & 15.669 & .221 & 5.318 \\
& & & & 3.958 \\
\hline Risk avoidance & 0.065 & 10.616 & .238 & 5.492 \\
& & & -.129 & 4.262 \\
& & & & -2.311 \\
\hline
\end{tabular}

The dep** significant at 0.05 level.

Moreover, Structural Equation Modelling (SEM) technique was used to fit the collected data to the conceptual model. The fitted model, presented in Table 3, has a good fit indices with all the fit-indices better than the recommended cut-off values; RMSEA $=.026$; (values close to zero indicate a better fit). $\mathrm{CFI}=.991$; NFI $=.9798$; GFI $=.995$; AGFI $=.963$ ). It is important to note that proposed model included the POR, Risk avoidance, PISO, Subjective financial literacy, intention and behaviour.

Table 3 depicts estimates for all paths modeled in the study.

Support was found for some of the research hypothesis, the results underscored direct association between POR and individuals intention towards stock market participation $(\beta=.24, p<.00)$. Also positive direct relation between Subjective financial literacy and intention $(\beta=.52, p$ $<.00$ ), further the there is a significant direct positive relation between PISO and intention $(\beta=0.12)$. Risk avoidance has a significant inverse relationship with intention. Alternatively, the hassle factor did not have a significant relationship with intention. Moreover, objective financial literacy and financial well-being did not have a significant relationship with either intention or behavior according to our proposed SEM. Therefore, our proposed model is illustrated in Figure 2.

Table 3. SEM results

\begin{tabular}{|c|c|c|c|c|c|c|c|}
\hline & & & Estimate & S.E. & C.R. & $\mathrm{P}$ & Accepted/ Rejected \\
\hline Intention & $<---$ & POR & .270 & .052 & 5.159 & $* * *$ & Accepted \\
\hline Intention & $<---$ & Riskavod & -.401 & .140 & -2.875 & .004 & Accepted \\
\hline Intention & $<---$ & SubFL & .893 & .105 & 8.480 & $* * *$ & Accepted \\
\hline Behavior & $<---$ & Intention & .017 & .007 & 2.357 & .018 & Accepted \\
\hline
\end{tabular}

Note: $\operatorname{RMSEA}=0.026,{ }^{* * *} p<0.00$. 


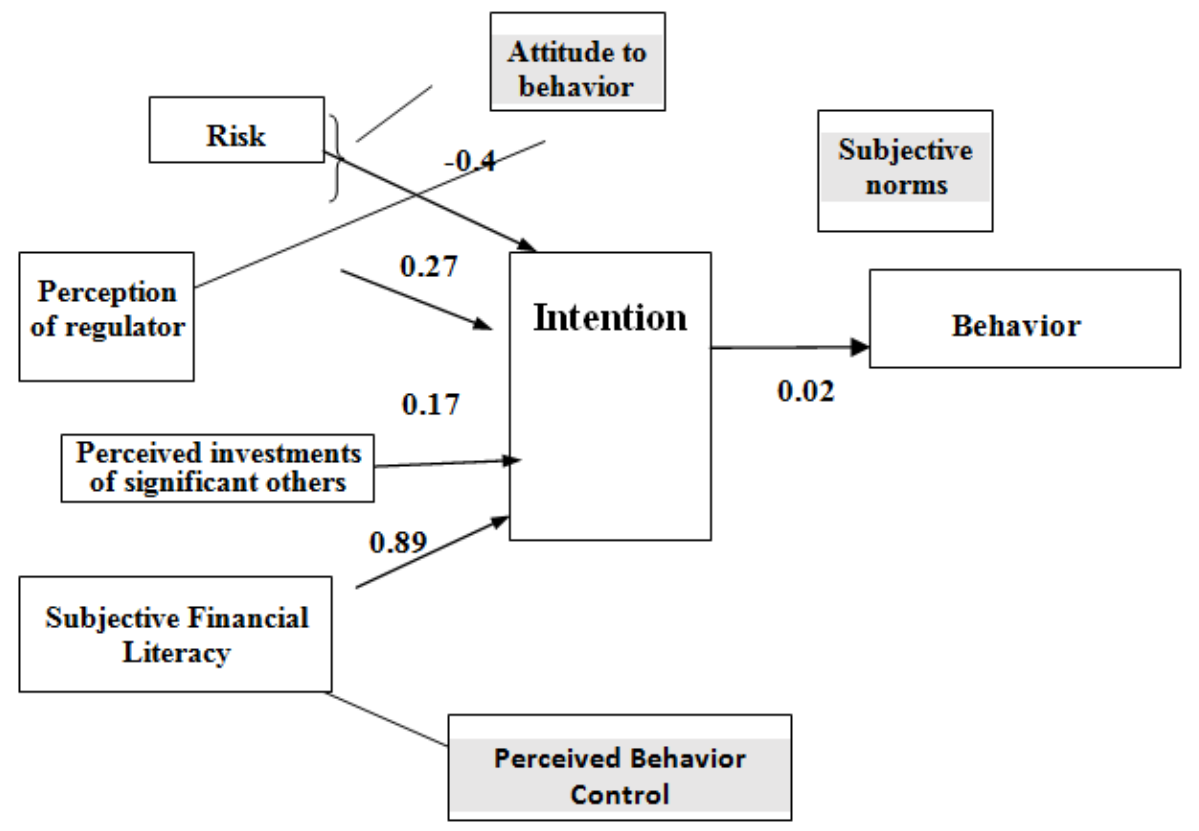

Figure 2. Proposed Model

\section{Discussion and Conclusion}

The present study contributes to the area of consumers' behavior and behavioral finance by studying drivers of stock market participation in a market rarely studied, using the theory of planned behaviour. A greater understanding of the variables in the model projected in this paper would aid regulators, policy makers and financial institutions in general to focus their efforts on the significant determinants of behavioral intentions' of individuals towards stock market participation in Egypt.

The results of the study generally is in line with Ajzen [16,24,47], May [48], Gopi and Ramayah [16], Farha [46] and who indicated the direct positive relationship of attitude, subjective norm and PBC.

The results of the study regarding the factors that predict investment intention was partially consistent with the study of Sivaramakrishnan and Rastogi [32], the study revealed that investment intention, in turn, was predicted by ATIB and variables pertaining to PBC, which included financial well-being, objective financial literacy, and subjective financial literacy. The Behavior, represented by equity holding was also predicted directly by financial well-being and objective financial literacy, this result is consistent with [30] which indicated that those with low literacy are much less likely to invest in stocks. However the results of our research indicating the variables representing the $\mathrm{PBC}$; the Subjective financial literacy was the only variable that predicts intention. This result was in line with Rooij et al., [30] who indicated that the low participation rate in stock market could be attributed to the perception of individuals regarding the difficulty of investing in stock market. POR and Risk avoidance were the only variables belonging to attitude to predict the intention. Furthermore, PISO can predict significantly the intention towards stock market participation. From this study, it can be concluded that stock market participation could be increased if the investors perceive that most of the people who are important to him/her want the investor to participate in stock market.
In addition, the only factors that can predict the behavior are POR and Risk avoidance, in which the latter result is similar to [49] that showed that, while imperfect, the measure of risk avoidance is related to financial behaviour and correlates with stock ownership. They concluded that those who are not willing to take risks are less likely to participate in the stock market. The result concerning the POR is consistent with Guiso and Sodini [1] and Cai [50].

We can argue that nowadays, with the continuous efforts done by the authorities to enhance stock market participation; as the amendments in the investment law, capital market law, timely announcements of the stock exchange news and cutting-edge trading technology, people do not suffer to collect the information they need. Thus, we do not consider the hassle factor as a significant predictor of the intention to participate in the stock market.

In this study, financial wellbeing was not presented, as one of the predictors of intention is consistent with [30]. We argue that, with respect to Egypt and despite the very high savings rates and the positive look for the future of investments, there is still a high preference to invest in real estate and gold or just deposit their savings in banks and enjoy a safe, relatively high interest rate.

Investment intention is found to be significantly and positively related to equity holding. This is as per the TPB where intention is expected to predict behavior [24]. This also agrees with the study done by East, [39], Sivaramakrishnan and Rastogi, [32] which used the TPB to explain investment behavior. This empirical model suggests that creating intention may be an antecedent to getting people to invest in equity products.

The results that indicated that $\mathrm{SN}$ represented by the variable PISO has an impact on intention directly is consistent with the TBP concluded by Ajzen [24], and inconsistent with Conner and Armitage [32,51].

Results from this study has shed light on which constructs can be better used to answer the managerial problem of factors influencing intention and behavior of stock market participation. 


\section{Limitations, Implications and Areas of Future Research}

\subsection{Limitations}

The results of this study should be interpreted with care given that this study was cross-sectional in nature, which means the inability to track the actual behavior of Egyptian investors. This would only have been feasible through a longitudinal study facilitated by a second round of surveys within the year, probably after the new amendments in investment law becomes more observable, with the introduction of the new investment vehicles promised as derivatives and the activation of more Islamic products alternatives as Sukuk. All of which may be more helpful in clarifying the behavior of investors in Egypt. In addition, caution should be taken when generalizing the model results in other countries since factors tested could be affected by the specific characteristics of the Egyptian market.

\subsection{Implications}

This study offers several valuable theoretical contributions through its originality of using the TPB to study investors' behavior towards stock market in Egypt. In addition, due to effect of stock market on enhancing the Egyptian economy; regulators, policy makers and institutions in Egypt could benefit through understanding the behavior of investors. Therefore, insights provided by this study could be used as a foundation to formulate strategies to increase stock market participation in Egypt.

We argue that the Egyptian government should be visible in such a way that any polices or disciplinary measures taken by market regulators should get sufficient publicity. Moreover, Information by the relevant others also could influence behavioral intention towards stock market participation. Banks, mutual funds, brokerage firms and other intermediaries could utilize incentives programs to the investors to increase stock market participation. Social pressure by the peers induced by the incentives could influence intention to buy stocks.

Subjective financial literacy in PBC also influences intention to participate in stock market. Stock brokerage houses can use marketing efforts and training to increase the level of PBC of investors and thus the probability of participating can be enhanced.

\subsection{Areas of Future Research}

By analysing a comprehensive list of stock market participation drivers and compares their explanatory power, we have concluded that behaviour is not only determined by those factors tested. Other moderating factors (as change in interest rates, taxes, and transaction costs) can be examined to test the effect on SMP. Our proposed model can be further tested across different developing markets as well of similar nature. Further research could also consider how Egyptian cultural and social perspectives and values affect the components of the TPB. Such studies will help regulators and institutions understand the various behavioral traits of investors, and thus devise effective strategies to attract and retain different investors. Future research could also test the demographics characteristics such as age, gender, occupation, income and education on investors' behavior towards stock market participation.

\section{References}

[1] Guiso, L. and Sodini, P. , "Household finance: an emerging field", in Constandinides, G., Harris, M. and Stulz, R. (Eds), Handbook of the Economics of Finance, Elsevier Science, Oxford, pp. 1397-1532, 2013.

[2] Hong, H., Kubik, J. D., \& Stein, J. C., "Social interaction and stock-market participation", The Journal of Finance, Vol. 60(1), pp. 137-163, 2004.

[3] Christiansen, C., Joensen, J. C., \& Rangvid, J., "Are economists more likely to hold stocks?" Review of Finance, vol. 12, pp.465-496, 2008.

[4] Grinblatt, M., Keloharju, M., \& Linnainmaa, J., "IQ and stock market participation", Journal of Finance, vol. 66(6), pp. 2121-2164, 2011

[5] Ülkü, N. and İkizlerli, D., "The interaction between foreigners' trading and emerging stock returns: Evidence from Turkey", Emerging Markets Review, Vol.13, pp. 381-409, 2011.

[6] Mecagni, Mauro and Sourial, Maged S., "The Egyptian Stock Market: Efficiency Tests and Volatility Effects," IMF Working Paper, pp. 1-30, 1999.

[7] Omran, M F., "Risk assessment of the Egyptian stock market in the wake of the Arab Spring", Journal of Economic and Administrative Sciences, Vol. 31 Issue: 2, pp.66-70, 2015.

[8] Wang, Z. W., \& Liao, L., "Financial literacy and stock market participation: Evidence from China." Working paper, Tsinghua University, 2013.

[9] Xia, T., Wang, Z. and Li, K. Soc Indic Res, "Awareness and stock market participation," Review of Finance, Vol. 9, pp. 537-567, 2014.

[10] Helmy, A. and Wagdi, O., "Political Risks and Their Economic Effects: Evidence from Egypt", International Journal of Economics and Finance, Vol. 8, No. 7, pp. 94-122, 2016.

[11] Metwally, AH. and Darwish, O., "Evidence of the overconfidence bias in the Egyptian stock market in different market states," The Business and Management Review, Vol. 6(4), pp. 178-198, 2015.

[12] Hirshleifer, D., "Investor psychology and asset pricing," The Journal of Finance, Vol. 56(4), pp.1533- 1597, 2001.

[13] Coval, J. D., and Shumway, T., "Do behavioral biases affect prices?” The Journal of Finance, Vol. 60(1), pp. 1-34, 2005.

[14] Hegner, Sabrina M., Fenko, Anna, and Teravest, Annemiek, "Using the theory of planned behaviour to understand brand love", Journal of Product \& Brand Management, Vol. 26 Issue: 1, pp.26-41, 2017

[15] Grønhøj, A. Bech-Larsen, T. Chan, K. and Tsang, L., "Using theory of planned behavior to predict healthy eating among Danish adolescents", Health Education, Vol. 113 Issue 1 pp. 4-17, 2013.

[16] Gopi, M. and Ramayah T., "Applicability of theory of planned behavior in predicting intention to trade online: Some evidence from a developing country", International Journal of Emerging Markets, Vol. 2 Issue: 4, pp.348-360, 2007.

[17] Shih, Ya-Yueh and Fang,Kwoting, "The use of a decomposed theory of planned behavior to study Internet banking in Taiwan", Internet Research, Vol. 14 Issue: 3, pp.213-223, 2004.

[18] Min, Soo, and James, Jeffrey, "The theory of planned behavior and intention of purchase sport team licensed merchandise", Sport, Business and Management: An International Journal, Vol. 6 Issue: 2, pp.228-243, 2016.

[19] Yadav, R., Chauhan, V. and Pathak, G.S., "Intention to adopt internet banking in an emerging economy: a perspective of Indian youth", International Journal of Bank Marketing, Vol. 33 No. 4, pp. 530-544, 2015.

[20] Fishbein, M. and Ajzen, I., "Belief, Attitude, Intention and Behavior: An Introduction to Theory and Research", AddisonWesley, Reading, MA, 1975.

[21] Jain, Sheetal, Khan Mohammed Naved, Mishra, Sita,, "Understanding consumer behavior regarding luxury fashion goods in India based on the theory of planned behavior", Journal of Asia Business Studies, Vol. 11 Issue: 1, pp.4-21, 2017. 
[22] Yen, C. and Chang, C.-M., "Unity is strength: understanding users' group buying behavior in Taiwan from a collectivism perspective", Journal of Electronic Commerce Research, Vol. 16 No. 2, pp. 109$122,2015$.

[23] Ajzen, I. and Fishbein, M., "Attitudes and the attitude-behavior relation: reasoned and automatic processes", in Stroebe, W. and Hewstone, M. (Eds), European Review of Social Psychology, Wiley, New York, NY, pp. 1-28, 2000.

[24] Ajzen, I., "The theory of planned behavior", Organizational Behavior and Human Decision Processes, Vol. 50, No. 2, pp. 179-211, 1991.

[25] Rimal, R., and Real, K., "How behaviours are influenced by perceived norms: A test of the theory of normative social behaviour". Communication Research, Vol. 32, pp.389-414, 2005.

[26] Dey, D.K., Chauhan, Y.K. and Chakraborti, R., "Does advertising strategy matter in influencing mutual fund purchase?", Journal of Financial Services Marketing, Vol. 20, No. 1, pp. 23-33, 2015.

[27] Lim, K.L., Soutar, G.N. and Lee, J.A., "Factors affecting investment intentions: a consumer behaviour perspective", Journal of Financial Services Marketing, Vol. 18, No. 4, pp. 301-315, 2013.

[28] Kaur, I and Kaushik, K.P. (2016) "Determinants of investment behaviour of investors towards mutual funds", Journal of Indian Business Research, Vol. 8 Issue: 1, pp.19-42

[29] Lusardi, A., Mitchell, O. , "Baby boomers retirement security: The role of planning, financial literacy and housing wealth", Journal of Monetary Economics, Vol.54, pp. 205-224, 2007.

[30] Rooij M.V., Lusardi, A. and Alessie, R., "Financial Literacy and Stock Market Participation". Michigan Retirement Center Research Center. Working Paper No.-162, 2007.

[31] Campbell, J., Household finance, Journal of Finance, 61, 15531604, 2006.

[32] Sivaramakrishnan S., Srivastava M. and Rastogi A., "Attitudinal factors, financial literacy and stock market participation." International Journal of Bank Marketing, Vol. 35 No. 5, 2017 pp. 818-841, 2016.

[33] Brown, J.R., Ivković, Z., Smith, P.A., Weisbenner, S.J., "Neighbours matter: causal community effects and stock market participation", Journal of Finance, Vol. 63, pp.1509-1531, 2008.

[34] Andrade, S. C., "A model of asset pricing under country risk", Journal of International Money and Finance, Vol. 28(4), pp.671-695, 2009.

[35] Harvey, C. R., "The world price of covariance risk", The Journal of Finance, Vol. 46(1), pp. 111-157, 1991.

[36] Heikki, L., and Kari, H., "Democracy, political risks and stock market performance", Journal of International Money and Finance, Vol. 59, pp. 77-99, 2015.

[37] Nebojsa, D., Vitaly, O., \& Vanja, P., "The political risk factor in emerging, frontier, and developed stock markets", Finance Research Letters, Vol.15, pp. 239-245, 2015.

[38] Bogan, V.L., "Household investment decisions", in Baker, H.K. and Ricciardi, V. (Eds), Investor Behavior: The Psychology of Financial Planning and Investment, Wiley, NJ, pp. 83-98, 2014.

[39] East, R., "Investment decisions and the theory of planned behavior", Journal of Economic Psychology, Vol. 14 No. 2, pp. 337-375, 1993.

[40] Xiao, J.J., Tang, C., Serido, J. and Shim, S., "Antecedents and consequences of risky credit behavior among college students: application and extension of the theory of planned behavior", Journal of Public Policy \& Marketing, Vol. 30 No. 2, pp. 239-245, 2011.

[41] Rutherford, L. and Devaney, S.A., "Utilizing the theory of planned behavior to understand convenience use of credit cards", Journal of Financial Counseling and Planning, Vol. 20 No. 2, pp. 48-63, 2009.

[42] Johnson, R.B., Onwuegbuzie, A.J. and Turner, L.A., "Toward a definition of mixed methods research", Journal of Mixed Methods Research, Vol. 1 No. 2, pp. 112-133, 2007.

[43] Raju, S.P. "Optimum stimulation level: its relationship to personality, demographics and exploratory behavior", Journal of Consumer Research, Vol.7 (3), pp. 272-282.

[44] Prawitz, A., Garman, E.T., Sorhaindo, B., O’Neill, B., Kim, J. and Drentea, P., "Incharge financial distress/financial well-being scale: development, administration, and score interpretation", Financial Counseling and Planning, Vol. 17 No. 1, pp. 34-50, 2006

[45] Mouna, Amari and Jarboui, Anis, "Financial literacy and portfolio diversification: an observation from the Tunisian stock market", International Journal of Bank Marketing, Vol. 33 Issue: 6, pp. 808-822, 2015.

[46] Farah, Maya F., "Application of the theory of planned behavior to customer switching intentions in the context of bank consolidations", International Journal of Bank Marketing, Vol. 35 Issue: 1, pp.147-172, 2017.

[47] Ajzen, I., "Constructing a TPB questionnaire: conceptual and methodological considerations", available at: http://chuang.epage.au.edu.tw/ezfiles/168/1168/attach/20/pta 411 76_7688352_57138.pdf, 2002 (accessed 30 March 2018).

[48] May, O.S., "User acceptance of internet banking in Penang: a model comparison approach", MBA thesis, School of Management, University Sains Malaysia, Penang, 2005.

[49] Barsky, R., Juster, F., Kimball, M., Shapiro, M., "Preference parameters and behavioural heterogeneity: an experimental study in the Health and Retirement Study". Quarterly Journal of Economics 112, 537-579, 1997.

[50] Cai, Wei, "State control and the weak stock market in China", Journal of Financial Crime, Vol. 17 Issue: 2, pp.179-194, 2010

[51] Conner, M. and Armitage, C.J., "Extending the theory of planned behavior: a review and avenues for further research", Journal of Applied Social Psychology, Vol. 28 No. 15, pp. 1429-1464, 1998.

[52] Behrman, J. R., Mitchell, O. S., Soo, C. K., \& Bravo, D., "How financial literacy affects household wealth accumulation", The American Economic Review, Vol. 102(3), pp.300-304, 2012.

[53] Francis, J.J., Eccles, M.P., Johnston, M., Walker, A., Grimshaw, J., Foy, R., Kaner, E.F.S., Smith, L. and Bonetti, D., "Constructing questionnaires based on the theory of planned behaviour: a manual for health services research", Quality of Life and Management of Living Resources, 2004.available at: http://bit.ly/2rHnQHc (accessed 20 June 2013).

[54] Heer, B. and Sussmuth B., "Effects of Inflation on Wealth Distribution: Do stock market participation fees and capital income taxation matter?" Journal of Economic Dynamics and Control, Vol.31 (1), pp.277-303, 2007.

[55] Linden, S., "Charitable Intent: A Moral or Social Construct? A Revised Theory of Planned Behavior Model" Curr Psychol, Vol.30, pp. 355-374, 2011.

[56] Lusardi, A., Bassa Scheresberg, C., "Financial literacy and highcost borrowing in the United States", No.w18969.National Bureau of Economic Research, 2013.

[57] Zhou, K.Z., Su, C. and Bao, Y., "A paradox of price - quality and market efficiency: a comparative study of the US and China markets", International Journal of Research in Marketing, Vol. 19 No. 4, pp. 349-365, 2002 